\title{
Copper reduces fertilisation success and exacerbates Allee effects in the field
}

\author{
Cam F. Hollows ${ }^{1}$, Emma L. Johnston ${ }^{1}$, Dustin J. Marshall ${ }^{2, *}$ \\ ${ }^{1}$ School of Biological, Earth and Environmental Sciences, University of New South Wales, Sydney, \\ New South Wales 2052, Australia \\ ${ }^{2}$ School of Integrative Biology/Centre for Marine Studies, University of Queensland, Queensland 4072, Australia
}

\begin{abstract}
The reproductive success of marine broadcast spawners depends on the concentration of sperm that surrounds eggs. Because sperm quickly dilute in the ocean, spawners must be sufficiently close to one another to ensure high rates of fertilisation. Thus, broadcast spawners can experience Allee effects - decreasing density can result in lower reproductive success because the costs of low fertilisation outweight any benefits of reduced intraspecific competition. Recently, there has been a dramatic increase in the number of studies examining the effects of toxicants on fertilisation success. These studies suggest that fertilisation is a highly sensitive stage and exposure to pollutants could severely reduce reproductive success in the field. However, we remain limited in our ability to predict the effects of toxicants under field conditions because most ecotoxicological studies utilise only a single sperm concentration. Moreover, all ecotoxicological studies of fertilisation to date have been limited to laboratory investigations, and it remains unclear whether the effects of a toxicant are overwhelmed in the dynamic and turbulent environment of the real world. We examined the effects of a common pollutant, copper, on the fertilisation success of the intertidal polychaete Galeolaria caespitosa in the laboratory and the field. In the laboratory, we examined the effects of copper over a range of sperm concentrations and in the field, we developed a new apparatus for examining fertilisation success in intertidal organisms. In the laboratory, copper had much stronger effects on fertilisation at low sperm concentrations than at high concentrations. We suggest that the use of single sperm concentrations in ecotoxicological assays of fertilisation is inappropriate because the magnitude of the effect of the toxicant can be estimated incorrectly. Copper also reduced fertilisation success in the field, with eggs having to be much closer to a sperm source in order to achieve any fertilisation success in the presence of copper. For populations of marine invertebrates in which reproduction is limited by sperm availability, the presence of a toxicant has the potential to dramatically reduce fertilisation success and greatly exacerbate Allee effects.
\end{abstract}

KEY WORDS: Ecotoxicology $\cdot$ Fertilisation kinetics $\cdot$ Polyspermy $\cdot$ Free-spawner $\cdot$ Pollution

\section{INTRODUCTION}

Most marine organisms reproduce by broadcast spawning, whereby they release sperm and eggs into the water column and fertilisation is external. Over the past $20 \mathrm{yr}$, interest in the consequences of this reproductive mode has greatly increased (Levitan \& Petersen 1995, Yund 2000, Levitan 2004). Intuitively one would expect that where fertilisation success (the percentage of eggs fertilised) is very low, then population growth rates will be tightly constrained by this initial lifehistory stage, and some scientists have suggested that the population dynamics of marine broadcast spawners will be sperm limited (Denny \& Shibata 1989, Levitan 1995, Levitan \& Petersen 1995). At the very least, variation in fertilisation success is likely to have important repercussions for the subsequent recruitment of individuals back into populations. Whilst data are limited, it does appear that fertilisation success can be highly variable within and among species of broadcast spawn- 
ers, and, in some instances, the majority of spawned eggs can remain unfertilised (Pennington 1985, Levitan et al. 1991, Coma \& Lasker 1997, Marshall 2002). A number of factors affect fertilisation success in broadcast spawners, but theoretical and empirical studies show that the most important factor is the concentration of sperm to which eggs are exposed (Vogel et al. 1982, Styan 1998, Millar \& Anderson 2003). Higher sperm concentrations result in higher fertilisation success, because eggs and sperm are more likely to come in contact with each other (Vogel et al. 1982, Millar \& Anderson 2003). However, at extremely high sperm concentrations, multiple sperm can contact the egg before the egg can produce a block to excess sperm, resulting in lethal polyspermy (Styan 1998). Local sperm concentrations are determined by water currents, water turbulence and, most importantly, the density of spawning males (Levitan 1991, Denny et al. 1992, Marshall 2002). Thus, reproductive success in marine broadcast spawners is strongly affected by population density. Higher densities generally lead to higher rates of fertilisation success, although very high densities may result in polyspermy (Brawley 1992, Franke et al. 2002, Marshall 2002). In other words, marine broadcast spawners can experience Allee effects, with higher population densities resulting in higher reproductive success due to higher rates of fertilisation outweighing any costs of competition (Allee 1931).

Given the potential importance of fertilisation success for the replenishment of marine populations, a number of studies have examined anthropogenic factors that mediate sperm concentrations and/or fertilisation success. For example, theoretical considerations have shown that commercial fishing can have strong negative effects on fertilisation success in broadcast spawners through decreases in the density of males (Quinn et al. 1993). However, one aspect of fertilisation success and Allee effects in broadcast spawners that has largely been overlooked is pollution. The twin processes of urbanisation and industrialisation continue to place significant pressure on nearshore marine ecosystems. Coastal waters are used as disposal mechanisms for the by-products of manufacturing, agriculture and domestic activities. As a consequence, marine organisms inhabiting these areas may be exposed to a historical legacy of pollution (in particular with regard to heavy metals), as well as ongoing effluent release. Although progress is being made, if we hope to successfully predict or ameliorate the negative impacts of pollution in these communities, more information regarding the effects of pollution on reproduction is required (ANZECC 2000).

Initial indications suggest that pollution is likely to have important consequences for reproductive success in broadcast spawners. Pollutants can greatly reduce population densities in marine communities (Johnston \& Keough 2002) and, thus, can increase the distance between spawning males and females, resulting in lower fertilisation rates. Furthermore, laboratorybased ecotoxicological studies suggest that the gamete/zygote stage of marine invertebrates is one of the most sensitive stages with regards to pollutants such as heavy metals (Dinnel et al. 1987, 1989, Ringwood 1992, Negri \& Heyward 2001, Reichelt-Brushett \& Harrison 2005, Reichelt-Brushett \& Michalek-Wagner 2005), and effects have been found at surprisingly low concentrations. Whilst these studies suggest that pollutants will strongly affect fertilisation success, we remain severely limited in our ability to make useful predictions about the likely impact of pollutants in the field for a number of reasons.

First, although early studies used multiple sperm concentrations (Dinnel et al. 1987, Ringwood 1992), most later studies use a single sperm concentration to determine the effects of the toxicant of interest (e.g. Zuniga et al. 1995, Negri \& Heyward 2001, ReicheltBrushett \& Michalek-Wagner 2005). Thus, it is difficult to determine whether the toxicant is affecting sperm viability, sperm-egg interactions (e.g. Franchet et al. 1999), or the polyspermy block (e.g. Franchet et al. 1997), all of which will manifest themselves in the same way-reduced fertilisation success (Millar \& Anderson 2003). Whilst these effects may seem similar, the ecological ramifications of each will vary dramatically. For example, if the pollutant reduces the effectiveness of polyspermy blocks (changes in the egg that prevent the entry of multiple sperms), the pollutant will have much stronger effects on high-density populations relative to low-density populations. Because high-density populations are more likely to suffer polyspermy in the first place, any reduction in the efficiency of polyspermy blocks will result in a higher proportion of eggs suffering fatal polyspermy. In contrast, if a pollutant affects sperm-egg attachment or sperm viability, then the pollutant will have the opposite effect: reproductive success will be reduced much more in low-density populations than in high-density populations. Thus, the consequences of pollution for population replenishment will strongly depend on the density of spawners and the aspect of fertilisation that the pollutant affects. The use of single sperm concentration assays does not provide sufficient information as to which aspect of fertilisation is being affected.

The second reason for our limited ability to predict the effects of pollutants on fertilisation success in the field is that all the studies thus far have been limited to the laboratory. Field examinations of fertilisation are generally rare, and so it is unclear whether toxicant effects in the laboratory are reflected in the field in the presence of (potentially overwhelming) factors such as turbulence 
and sperm dilution effects (Levitan 1991, Levitan et al. 1991, Mead \& Denny 1995). If we hope to predict the effects of pollutants under real-world conditions, laboratory tests using a range of sperm concentrations and field tests under realistic contingencies are crucial.

Here, we examine the effect of a common marine pollutant, copper, on the fertilisation success of the broadcast-spawning polychaete Galeolaria caespitosa. Previous studies have shown that spawned eggs are more likely to remain in situ and spawned sperm will quickly dilute to ineffective concentrations (Marshall 2002, Marshall et al. 2004). Given that eggs can remain in the environment for longer periods than sperm, we were also interested in whether previous exposure of eggs to a toxicant could affect fertilisation in G. caespitosa. We first determined the relative sensitivity of unfertilised eggs versus eggs and sperm at fertilisation to copper at a range of sperm concentrations. We then developed a field assay technique for intertidal broadcast spawners and conducted the first field examination of the effects of a pollutant on fertilisation success in the field. We found that copper strongly affects fertilisation success in a manner that will exacerbate Allee effects: low-density populations will experience greater reductions in fertilisation success than highdensity populations.

\section{MATERIALS AND METHODS}

General methods: study species and site. Galeolaria caespitosa is a common intertidal polychaete along southern and eastern Australian coasts. This species occurs at a range of densities from sparse individuals spread out over a hard surface to dense 3-dimensional clusters growing on the calcareous tubes of dead individuals. For the collection of reproductively mature individuals and for our field trials, we used Dolls Point Pier in Botany Bay, New South Wales, Australia (33⒌ $59^{\prime} 9^{\prime \prime} \mathrm{S}, 151^{\circ} 8^{\prime} 7^{\prime \prime} \mathrm{E}$ ). This pier was chosen because it is a relatively sheltered site, has high densities of $G$. caespitosa and in terms of our chosen toxicant, copper, is a relatively unpolluted site $\left(<5 \mu \mathrm{g} \mathrm{Cu} \mathrm{l}^{-1}\right.$; E. L. Johnston unpubl. data). To collect adults, we pried chunks of worm clusters from the pier pilings and maintained them in aquaria in the laboratory at a constant temperature of $19^{\circ} \mathrm{C}$ and in a photocycle of $16 \mathrm{~h}$ light: $8 \mathrm{~h}$ dark. To collect gametes, we used the standard technique described by Marshall \& Evans (2005). All experiments were performed with aged (12 h), $0.45 \mu \mathrm{m}$ filtered seawater (AFSW) collected from Clovelly Bay

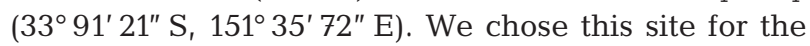
collection of water because there are very few $G$. caespitosa in the area (minimising the chances of sperm contamination) and it is well flushed by oceanic waters.
Equipment preparation and toxicant dosing. All experimental equipment was acid washed in 5\% nitric acid for $>24 \mathrm{~h}$ and rinsed twice in MilliQ water prior to use. Analytical-reagent grade $\mathrm{CuSO}_{4}$ (Copper II sulphate anhydrous, Sigma Chemicals) was used as the reference toxicant for all experiments. For laboratory experiments, a $1000 \mu \mathrm{g} \mathrm{Cu} \mathrm{l}^{-1}$ solution was prepared at the beginning of each experimental run from a refrigerated stock solution and diluted with AFSW to make 3 nominal pre-soaking solutions of 10,25 and $50 \mu \mathrm{g}$ $\mathrm{Cu} \mathrm{l}^{-1}$. Treatment concentrations were selected on the basis that they approximately equate to (1) a pristine toxicant-free ocean sample (control), (2) twice the Australian Water Quality trigger guideline for copper in marine waters $\left(10 \mu \mathrm{g} \mathrm{Cu} \mathrm{l}^{-1}\right.$; ANZECC 2000), (3) the background concentrations in a polluted industrial harbour (25 $\mu \mathrm{g} \mathrm{Cu} \mathrm{l}^{-1}$; Hall et al. 1998) and (4) the copper concentration in a very polluted harbour or

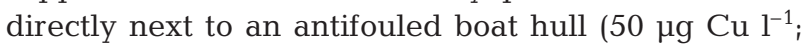
Haynes \& Loong 2002). Experimental containers were pre-soaked in the appropriate treatment concentration for $12 \mathrm{~h}$ prior to each run to minimise the reduction in copper via chelating to experimental containers (Batley et al. 1999). Samples of each of these treatment solutions were acidified and refrigerated prior to analysis of total copper by Inductively Coupled PlasmaAtomic Emission Spectrometry (ICP-AES). Metal analyses were carried out at the Australian National Association of Testing Authorities accredited National Measurement Institute (NMI). A random subset of samples $(n=16)$, representing all treatments across a number of runs, were submitted for analysis to ensure quality control, and all were within 15\% (all but 3 samples were within $10 \%$ ) of the nominal concentration. A single toxicant concentration was used in the field experiment (50 $\mu \mathrm{g} \mathrm{Cu}^{-1}$ see section 'Expt 2: effects of copper on fertilisation in the field').

Laboratory fertilisation assays. We used serial, 10fold dilutions of sperm collected from 5 to 10 individual males and pooled. For our laboratory assays, we used sperm concentration ranges between 10 and $10^{6}$ sperm $\mathrm{ml}^{-1}$. Sperm counts were done with an improved Neubauer haemocytometer at 40× magnification (3 replicate counts per experimental run). Eggs were collected from 5 to 10 females and pooled. The density of eggs between different experimental runs was allowed to vary (range: 200 to 1000 eggs $\mathrm{ml}^{-1}$ ), but was internally consistent within each run. Within each vial, the final volume, which included the toxicant (where appropriate), sperm solution and egg solution, was $10 \mathrm{ml}$ throughout the laboratory assays. Care was taken to ensure that the vials were interspersed such that treatments were not clumped. Throughout the laboratory experiments, eggs were exposed to the sperm solutions for $2.5 \mathrm{~h}$, to allow development to begin, and 
were kept at $\sim 20^{\circ} \mathrm{C}$. This period probably represents the maximum period for which eggs are likely to remain before an incoming tide disperses them (Marshall 2002). After this period, the eggs were fixed with a few drops of $18 \%$ (vol/vol) formalin solution. To assay fertilisation success, eggs were classified as fertilised as described in Marshall \& Evans (2005), and 200 randomly chosen eggs in each replicate were examined for fertilisation. We classified eggs as 'fertilised' if they had begun cell division into 2 cells and as 'unfertilised' if they showed no sign of cleavage. Note that this classification does not distinguish between failure to fertilise and failure to develop, but the ecological consequences are identical-no larvae will be produced. In every experimental run, an egg 'control' was set aside that was not exposed to any sperm solutions to check for errant fertilisations during the collection of gametes. If a sample showed $>3 \%$ fertilisation, that run was discarded $(\mathrm{n}=1)$.

Expt 1a: exposure to copper at fertilisation. For this experiment, eggs and sperm were exposed to the toxicant solution simultaneously at fertilisation, and any subsequent development took place in the copper solution. Each experimental run in the laboratory consisted of an array of different sperm and toxicant concentrations. As described in the general methods, there were 5 sperm concentrations and 4 toxicant concentrations (including the control), yielding 20 different treatment combinations. For each treatment combination, we used 2 replicate vials yielding a total of 40 vials per experimental run. We conducted 9 experimental runs in total, each run from a different collection of gametes.

Expt 1b: exposure of eggs to copper before fertilisation. For this experiment, eggs were exposed to the toxicant solution (or the control) for $3 \mathrm{~h}$ prior to exposure to sperm. After the $3 \mathrm{~h}$ exposure, but before being exposed to the sperm solution, we gently rinsed the eggs in AFSW on a $25 \mu \mathrm{m}$ mesh to remove the toxicant solution and then placed them into a fresh solution of AFSW. It should be noted that the sperm used for this experiment was not old sperm but collected freshly as in Expt 1a. As in the first part of Expt 1, there were 5 sperm concentrations and 4 toxicant concentrations (including the control), yielding 20 different treatment combinations. For each treatment combination, we used 2 replicate vials, yielding a total of 40 vials per experimental run. We did 5 experimental runs in total for this part of the experiment.
Expt 2: effects of copper on fertilisation in the field. Because Galeolaria caespitosa is an intertidal organism, we could not use existing methods for conducting field fertilisation experiments and had to develop an array that reflected the fact that spawning probably occurs in the intertidal (Marshall 2002). We created 'egg pots' that were pieces of $600 \mathrm{~mm}$ long, $20 \mathrm{~mm}$ diameter PVC piping, with 1 end covered in $45 \mu \mathrm{m}$ mesh (Fig. 1). This end was removable so that any eggs sitting at the base ( $G$. caespitosa eggs are negatively buoyant) could be sampled easily. The egg pots were attached to pier pilings along a piece of larger (40 mm diameter PVC) pipe forming a frame, so that the pots were held in a row. Each pot was separated by $50 \mathrm{~mm}$, and the pots started $10 \mathrm{~mm}$ from the centre of the frame and extended out to $260 \mathrm{~mm}$ from the centre of the frame. The pots extended out from the centre of the frame in both directions, and the frame was oriented so that there was a leeward (towards shore) and seaward (towards the sea) orientation of the egg pots and frame. We constructed 2 of these arrays and attached each of them to different pier pilings with elastic cord (separated by $4 \mathrm{~m}$ ). The egg pots and frame were at a depth so that the bottoms of the pots were submerged to

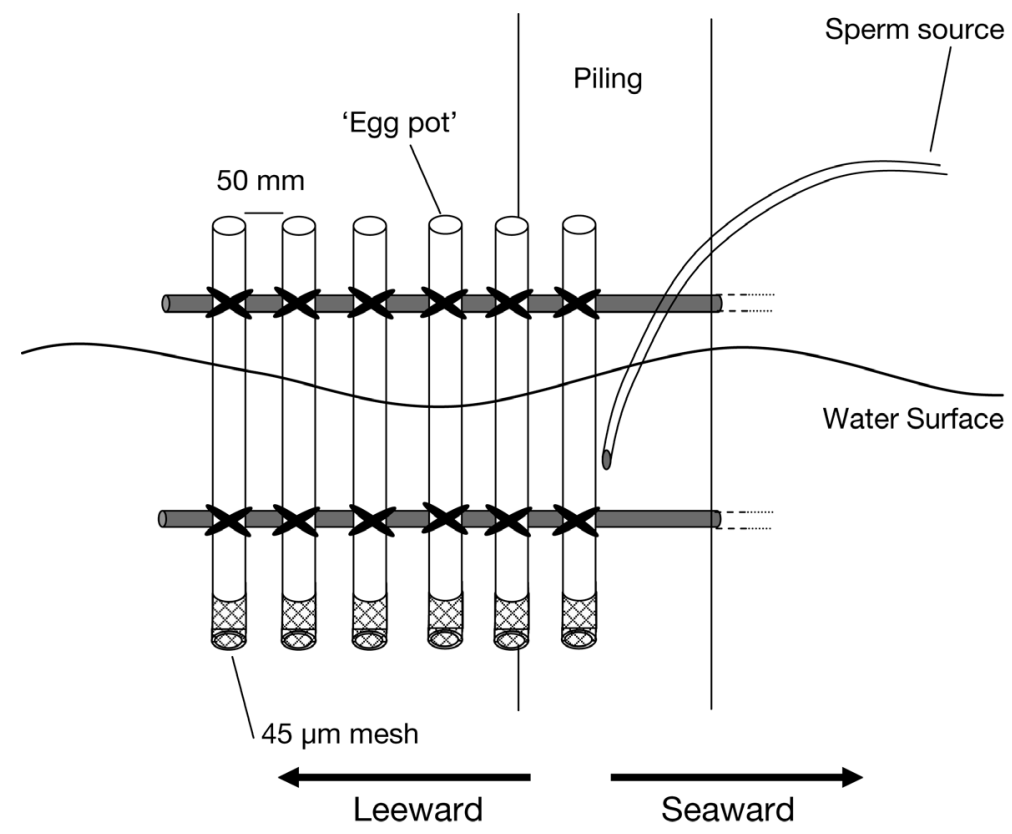

Fig. 1. Schematic of half of the field array used to examine the effects of copper on fertilisation success in the field for Galeolaria caespitosa eggs. The base of each pipe ('egg pots') was removable, submerged in the water and covered with $45 \mu \mathrm{m}$ mesh. The eggs sat in the base of the egg pots and as seawater moved up and down in the pipe (with the movement of waves) sperm was brought past the eggs. The egg pots were spaced $50 \mathrm{~mm}$ apart, starting $10 \mathrm{~mm}$ from the sperm release point and extended to both sides of the sperm release point (leeward and seaward). For any single experimental run, there were 2 arrays: one in which copper was incorporated in the sperm solution and another with a control sperm solution 
about $100 \mathrm{~mm}$ under the surface of the water. However, the depth this close to the shore (the arrays were place $20 \mathrm{~m}$ from the shore) was highly variable at a small scale so that with each small wave the bottoms of the pots were often exposed or submerged to about $300 \mathrm{~mm}$ depth. Care was taken to ensure that the tops of the egg pots were always higher than the highest wave. Thus, the movement of the water height caused water to move in and out of the egg pots through the mesh base, carrying any sperm with it. This height on the pier piling simulates the amount of water exposure G. caespitosa colonies experience in the middle of a tidal cycle. We believe that this artificial array closely simulates the spawning of eggs in the wild and the retention of eggs for a brief period on the adults where the eggs accumulate fertilisations. However, it should be noted that this apparatus probably does not perfectly replicate natural conditions and, thus, is only a relative measure of fertilisation success.

As in our laboratory experiments, we collected eggs from 5 to 10 females, but, for this experiment, we spawned the females out in the field. We placed $2 \mathrm{ml}$ of egg solution in each egg pot and then collected sperm from males. Egg collection and deployment took 15 min, and we used the sperm solutions within 15 min of spawning the males.

At the centre of our frames, we secured a piece of $5 \mathrm{~mm}$ diameter plastic tubing that was connected to a $60 \mathrm{ml}$ syringe. To release sperm into our arrays, we filled the $60 \mathrm{ml}$ syringes with either a sperm solution (final concentration $\sim 10^{8}$ sperm $\mathrm{ml}^{-1}$ collected from 5 to 10 males and variable among runs) or the sperm solution (at an identical concentration within each experimental run) in a seawater solution containing $50 \mu \mathrm{g}$ $\mathrm{Cu} \mathrm{l}^{-1}$. The plastic tubing allowed us to release the solutions simultaneously in the 2 arrays without disturbing the motion of water surrounding the 2 arrays. We released the solutions by depressing the plungers of the syringe slowly over a $10 \mathrm{~s}$ period, immediately re-filled the syringes with fresh seawater and again depressed the plunger to expel any remaining solution left in the tubing lines. We randomly assigned the $\mathrm{Cu}$ and control treatments to the different arrays for each experimental run. We left the eggs in the egg pots for 15 min after sperm release, after which the eggs were rinsed with AFSW, placed into their own $70 \mathrm{ml}$ jars, allowed to develop for a further $2 \mathrm{~h}$ and then fixed with a few drops of formalin. Fertilisation success was then assayed as in the laboratory experiments. We performed 8 separate field trials, using different sperm/egg solutions, with the first trials performed in September 2005 and the last in February 2006. One trial showed errant fertilisations, indicating contamination with sperm during the collection of eggs and so was removed from the final analysis.
Statistical analysis. For all the analyses, we used untransformed, proportion data rather than arcsine, square-root-transformed data. In some instances, the data were not normally distributed. We used the raw data because our data were balanced and transformation did not improve the distribution of the data (Quinn \& Keough 2002). When sperm concentration was included as a factor, we used log sperm concentration in our analyses.

To analyse the effects of copper exposure during fertilisation for Galeolaria caespitosa, we used a mixed linear model in which copper concentration and sperm concentration were continuous factors and experimental run was a random, categorical factor. We first tested for interaction between run and the continuous factors, this was not significant $\left(F_{8,324}=0.31, \mathrm{p}=0.96\right)$ and was removed from the final model.

To analyse the effect of exposing eggs to copper before fertilisation, we could not use raw data because, for these experiments, the relationship between sperm concentration and fertilisation was not linear. Instead we used the standard summary statistics for fertilisation curves $-F_{\max }$ and $[\text { Sperm }]_{\max }$ (Marshall 2006). $[\text { Sperm }]_{\max }$ is the sperm concentration that maximises fertilisation success (i.e. the 'fertilisability' of eggs), and maximum fertilisation success $\left(F_{\max }\right)$ estimates egg viability (Marshall 2006). We analysed each of these response variables using a mixed, linear model in which copper concentration was a continuous factor and run was a random, categorical factor. For both $F_{\max }$ and $[\text { Sperm }]_{\max }$, the interactions between run and copper concentration were not significant so they were omitted from the final model ([Sperm $]_{\text {max }}$ : $p=0.147$; $F_{\text {max }}: \mathrm{p}=0.841$ ).

To analyse the effect of copper on fertilisation success in the field, we used a mixed linear model in which egg pot distance from the sperm source was a continuous factor, copper treatment was a fixed, categorical factor and experimental run was a random, blocking factor. It should be noted that 'run' incorporates temporal variation and any variation due to differences in initial sperm concentrations among runs. Whilst it could be argued that a run $\times$ treatment interaction could be estimated from our design (see Quinn \& Keough 2002, p. 357), we believe a more conservative approach is to treat our analysis as an unreplicated block design; thus, the model did not estimate the interaction between run and any other factor. We initially included a fourth categorical factor, direction (seaward vs. leeward), in the analysis, but it explained little variation and was of little biological interest so it was removed from the final model. In order to create a more conservative analysis, we then pooled the seaward and leeward replicates into a single mean value so that our main effects were not 
tested over a potentially inflated number of degrees of freedom. We simplified the model by removing nonsignificant interactions between any factor and the continuous factor (Quinn \& Keough 2002), and the non-significant term $(\mathrm{p}=0.884)$ distance $\times$ treatment was also removed.

\section{RESULTS}

\section{Expt 1a: effect of copper exposure at fertilisation}

Generally sperm concentration had very strong effects on fertilisation success, with higher sperm concentrations resulting in higher fertilisation success across treatments. Overall, there appeared to be a strong effect of copper on fertilisation success in Galeolaria caespitosa, with fertilisation rates being lower in the presence of copper (Fig. 2). However, as revealed by the interaction between sperm concentration and treatment, this effect depended on sperm concentration, and therefore the interpretation of main effects should be treated with caution (Table 1). The effects of copper were greatest at the lowest sperm concentrations, with a 2-fold reduction in fertilisation success relative to the controls. At high sperm concentrations, however, copper had little to no effect on fertilisation (Fig. 3).

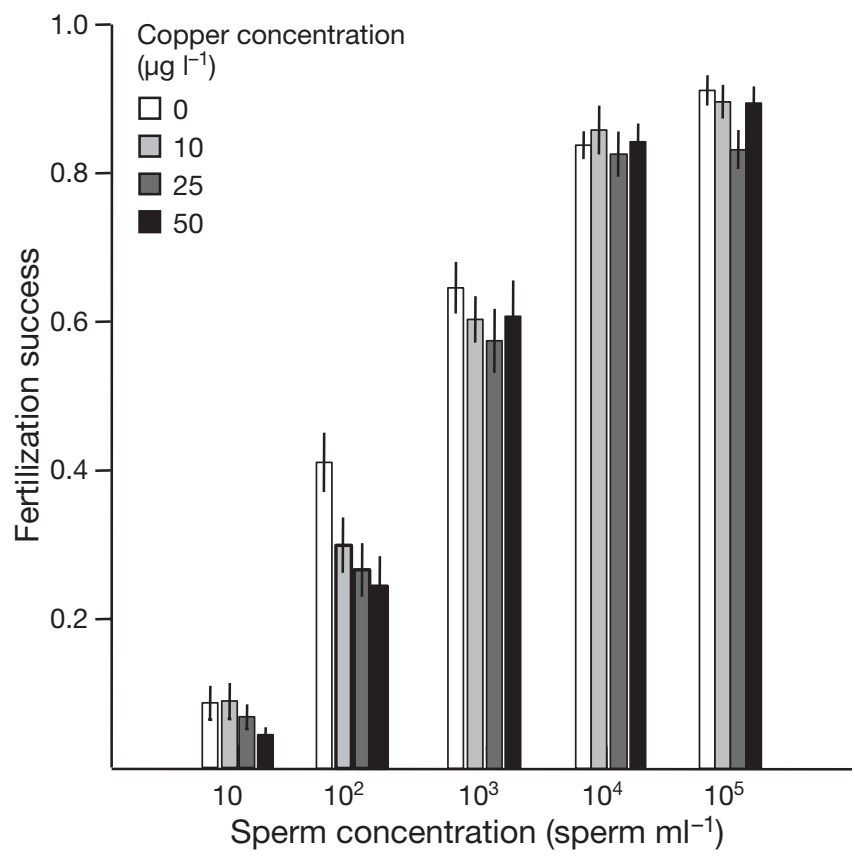

Fig. 2. Galeolaria caespitosa. Effect of exposure to copper at fertilisation on mean $( \pm$ SE within groups) fertilisation success of eggs in the laboratory. Bars show results across the sperm concentrations used in the experiment (log scale); open bars indicate samples at $0 \mu \mathrm{g} \mathrm{Cu} \mathrm{l^{-1 }}$, whilst shaded bars indicate samples at 10, 25 and $50 \mu \mathrm{g} \mathrm{Cu} \mathrm{l}^{-1}$. Data were pooled across different experimental runs
Table 1. Galeolaria caespitosa. Linear mixed model examining fertilisation success under different sperm concentrations (conc.) and copper concentrations $\left(0,10,25,50 \mu \mathrm{g} \mathrm{l}^{-1}\right)$. Significant $\mathrm{p}$-values in bold. Model is reduced after testing for nonsignificant interactions (see 'Materials and methods')

\begin{tabular}{|lcccr|}
\hline Source & df & Mean square & $F$-ratio & \multicolumn{1}{c|}{$\mathrm{p}$} \\
\hline Treatment (T) & 1 & 0.239 & 18.3 & $\mathbf{0 . 0 0 3}$ \\
Run (R) & 8 & 0.119 & 7.5 & $<\mathbf{0 . 0 0 1}$ \\
Sperm conc. (S) & 1 & 13.600 & 178.9 & $<\mathbf{0 . 0 0 1}$ \\
$\mathrm{R} \times \mathrm{T}$ & 8 & 0.013 & 0.8 & 0.604 \\
$\mathrm{R} \times \mathrm{S}$ & 8 & 0.076 & 4.7 & $<\mathbf{0 . 0 0 1}$ \\
$\mathrm{S} \times \mathrm{T}$ & 1 & 0.107 & 6.7 & $\mathbf{0 . 0 1 0}$ \\
Residual & 332 & 0.016 & & \\
& & & & \\
\hline
\end{tabular}

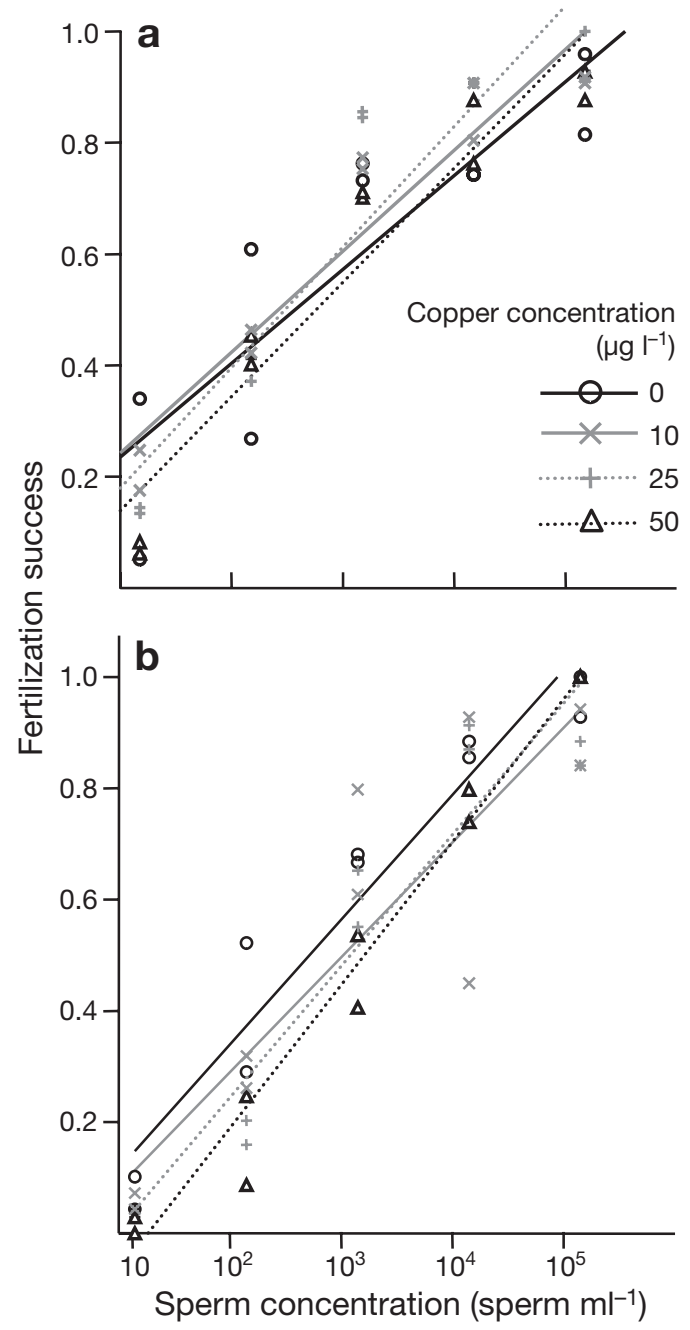

Fig. 3. Galeolaria caespitosa. Effect of exposure to copper at fertilisation on fertilisation success for experimental Runs (a) 5 and (b) 7. The $x$-axis shows sperm concentration (log scale), and the lines represent best fit for each copper concentration $\left(0,10,25,50 \mu \mathrm{g} \mathrm{Cu} \mathrm{l}^{-1}\right)$. Each point represents a single replicate for that sperm/copper combination. At low sperm concentrations, fertilisation success was roughly halved by the presence of copper, but at high sperm concentrations, copper had little to no effect 


\section{Expt 1b: effect of pre-exposing eggs to copper}

There was no effect of pre-exposing eggs to copper on either $[\mathrm{Sperm}]_{\max }$ or $F_{\max }$. The mean $( \pm \mathrm{SE})$ maximum fertilisation success $\left(F_{\max }\right)$ for eggs exposed to $50 \mu \mathrm{g} \mathrm{Cu} \mathrm{l}^{-1}$ was $94 \%( \pm 3.7)$ compared to the controls $95 \%( \pm 3.8)$. There was no trend for any effect, with the only significant differences in fertilisation success occurring among different experimental runs (Table 2).

\section{Expt 2: effects of copper on fertilisation success in the field}

There was a strong effect of copper on fertilisation success of Galeolaria caespitosa eggs in the fieldfertilisation success in the copper treatment was, on average, half that of the control treatment (Fig. 4, Table 3). Fertilisation success decreased with distance from the sperm source; fertilisation success was $\sim 25 \%$ almost adjacent $(10 \mathrm{~mm})$ to the sperm source and was $<5 \%$ at the furthest point from the sperm source $(260 \mathrm{~mm})$. This pattern was consistent irrespective of the presence/absence of copper (Fig. 4).

\section{DISCUSSION}

The presence of copper at low concentrations during fertilisation had strong effects on fertilisation success in the laboratory and in the field. This is the first study to show an effect of a pollutant on fertilisation success under field conditions for any marine organism and suggests that even low levels of pollution could have significant impacts on the reproductive success of freespawning organisms. Given that we found strong reductions in fertilisation success at relatively low concentrations ( 25 to $50 \mu \mathrm{g} \mathrm{Cu} \mathrm{l}^{-1}$ ), sites with even minor levels of pollution could have substantially lower rates of fertilisation. Clearly, toxicants have the potential to greatly exacerbate Allee effects in marine broadcast spawners.

To examine the effects of copper on fertilisation success in the field for Galeolaria caespitosa, we could not use field arrays that have been developed previously because these have been specifically designed for subtidal or completely submerged organisms (e.g. Babcock \& Mundy 1992). G. caespitosa are intertidal, and recent evidence suggests that intertidal organisms spawn at, or around, low tide (Williams et al. 1997, Brawley et al. 1999, Marshall 2002), and, in these species, spawned eggs have been noted to remain near or on the spawning females. There are no data on natural G. caespitosa spawning events, but we felt that an apparatus that reflected the fact that eggs are probably spawned and retained briefly in the intertidal zone was required. We
Table 2. Galeolaria caespitosa. Linear mixed model examining (a) egg viability $\left(F_{\max }\right)$ and $(b)$ the sperm concentration that maximises fertilisation success ([Sperm $]_{\max }$ ) of eggs that had been treated with copper $\left(0,10,25,50 \mu \mathrm{g} \mathrm{l}^{-1}\right)$ for $3 \mathrm{~h}$ prior to being exposed to sperm. Significant p-values in bold. Model was reduced after testing for non-significant interactions (see 'Materials and methods')

\begin{tabular}{|lcccc|}
\hline Source & df & Mean square & F-ratio & $\mathrm{p}$ \\
\hline (a) $\boldsymbol{F}_{\text {max }}$ & & & & \\
$\quad$ Treatment & 1 & 14.78 & 1.96 & 0.183 \\
Run & 4 & 27.16 & 3.6 & $\mathbf{0 . 0 3 2}$ \\
$\quad$ Residual & 14 & 7.54 & & \\
(b) [Sperm] & & & & \\
$\quad$ Treatment & 1 & 2.68 & 1.11 & 0.310 \\
Run & 4 & 2.05 & 0.85 & 0.517 \\
Residual & 14 & 2.42 & & \\
\hline
\end{tabular}

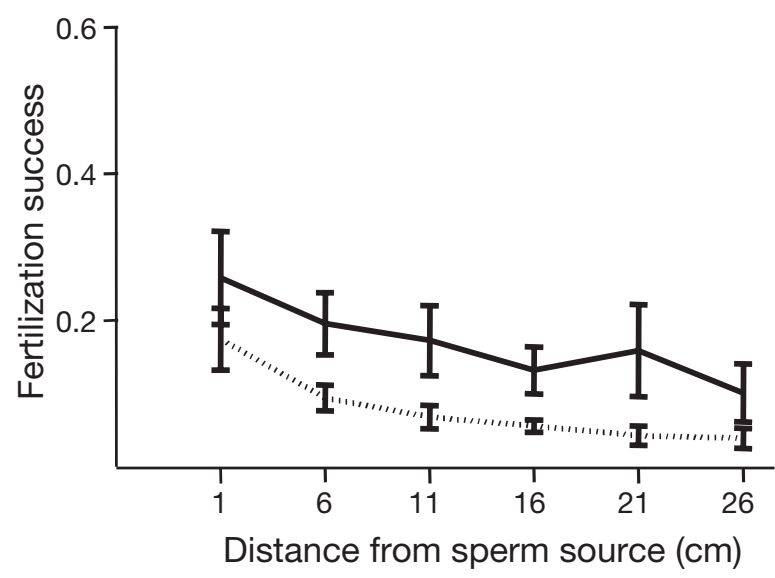

Fig. 4. Galeolaria caespitosa. Effect on fertilisation success of eggs in the presence (............) and absence (- $)$ of $50 \mu \mathrm{g}$ $\mathrm{Cu} \mathrm{l}^{-1}$ solution when released with sperm in the field. The $\mathrm{X}^{-}$ axis shows distance from sperm release point, data are pooled for both seaward and leeward directions and pooled across different experimental runs (see 'Materials and methods'). Each point represents mean fertilisation success $( \pm$ SE within groups)

Table 3. Galeolaria caespitosa. Linear mixed model examining fertilisation success of eggs in the field at different distances from a sperm source in the presence and absence of copper (initial concentration $50 \mu \mathrm{g} \mathrm{l}^{-1}$ ). Significant $\mathrm{p}$-values in bold. Model was reduced after testing for a non-significant interaction (see 'Materials and methods')

\begin{tabular}{|lcccc|}
\hline Source & df & Mean square & $F$-ratio & $p$ \\
\hline Run & 7 & 842 & 9.6 & $<\mathbf{0 . 0 0 1}$ \\
Treatment & 1 & 1212 & 13.8 & $<\mathbf{0 . 0 0 1}$ \\
Distance & 1 & 1609 & 18.3 & $<\mathbf{0 . 0 0 1}$ \\
Residual & 84 & 87 & & \\
\hline
\end{tabular}


suggest that our new array could be a useful piece of equipment for examinations of fertilisation success in the intertidal - a habitat that has largely been ignored in terms of manipulative experiments. Our experiments in the field differ from traditional ecotoxicological studies in that we cannot be certain of the exact copper concentration present when the sperm contacts the eggs. We do, however, know that the copper concentration was $<50$ $\mu \mathrm{g} \mathrm{l}^{-1}$, and we believe that the benefits of increased ecological realism outweigh the costs of ambiguity regarding the final toxicant concentration.

In the experiments in which we exposed eggs to copper before fertilisation, we found no effect on [Sperm] $]_{\max }$ or $F_{\max }$ (egg 'fertilisability' or egg viability, respectively). Several studies have suggested that eggs remain in situ after spawning for much longer than sperm (Williams et al. 1997, Meidel \& Yund 2001, Marshall 2002) and also have much greater longevity than sperm. With this increased residence time comes the increased risk of being exposed to a pollutant or toxicant. However, it appears that for Galeolaria caespitosa, at the concentrations of copper used in this study, the fertilisation potential of eggs is not reduced by pre-exposure to copper. From this result, it is tempting to infer that, because we saw strong effects of copper when eggs and sperm were present but did not see an effect on eggs alone, sperm are sensitive to copper, but eggs are not. However, it is premature to state that the effects of copper on fertilisation act through effects on sperm alone. For example, eggs could still be sensitive, but only at the moment of fertilisation (given that fertilisation is usually associated with a change in membrane permeability to ions this is possible; Franchet et al. 1997). Whilst we cannot determine the specific effect of copper on fertilisation, it is clear that the magnitude of its effects in G. caespitosa are sperm concentrationdependent, with stronger effects at low sperm concentrations dependant, than at high sperm concentrations (Figs. $2 \& 3$ ). This sperm concentration-specific effect strongly suggests that copper reduces fertilisation success through the reduction of successful sperm-egg interactions (Millar \& Anderson 2003). This reduction could come about due to copper killing sperm or reducing the efficiency of sperm-egg contacts (Franchet et al. 1999). Regardless of the mechanism, this sperm concentration-dependent effect has a number of implications both for ecotoxicology and for the fertilisation ecology of broadcast spawners more generally.

\section{Potential implications for ecotoxicology}

The first implication of our toxicant having different effects at different sperm concentrations is based on previous assays examining the effect of toxicants on fertilisation. Many of these assays use sperm concentrations that result in $\sim 80 \%$ fertilisation in the control (reviewed in Marshall 2006). The sperm required to achieve $>80 \%$ fertilisation almost certainly will also result in some polyspermy (Styan 1998, Millar \& Anderson 2003). Thus, if these studies utilise toxicants that reduce sperm-egg contact rates, then polyspermy will also be reduced by toxicant exposure and the overall effect on fertilisation success may appear negligible. If these results are then used to predict the effects of the toxicant on fertilisation at lower sperm concentrations, toxicity will be dramatically underestimated (conversely, if the toxicant reduces the efficiency of polyspermy blocks, the effect will be dramatically overestimated; reviewed in Marshall 2006). For example, if we had only conducted our experiments at a high concentration, we would have dramatically underestimated the effect of copper on fertilisation. Only by using a range of sperm concentrations can the effect of a toxicant be reliably estimated. Dinnel et al. (1987) made this point almost $20 \mathrm{yr}$ ago, but since then ecotoxicological fertilisation assays have largely focused on a single concentration. Our study supports the data presented by Dinnel et al. (1987) and the conceptual arguments proposed by Marshall (2006). Given that the concentration of sperm required to achieve a high level of fertilisation will vary widely among and even within species (Marshall \& Evans 2005), estimates of sensitivity to toxicants among species are almost impossible to compare if only a single sperm concentration is used.

\section{Implications for the reproductive success of broadcast spawners}

Because at low sperm concentrations fertilisation was more affected by copper than at high sperm concentrations, unlike some other heavy metals (e.g. mercury; Franchet et al. 1997), it appears that copper does not reduce the effectiveness of polyspermy blocks in Galeolaria caespitosa. Thus, copper will have the most negative effects on fertilisation success in low-density, sperm-limited populations. For G. caespitosa, it seems that sperm dilutes to low concentrations so quickly in the field that the fertilisation success of eggs only centimetres from the release point of sperm is sperm limited, despite the sperm of $\sim 10$ males being released adjacent to these eggs. Thus, even at very high population densities, fertilisation success in this species is likely to be severely reduced by pollutants.

The impact of copper in the field was, effectively, to reduce the distance between a spawning male and female at which fertilisation is assured. For example, for eggs to achieve $\sim 10 \%$ fertilisation success under 
ambient conditions, eggs could be up to $26 \mathrm{~cm}$ from the sperm release point. In contrast, when exposed to copper, eggs could be no further than $6 \mathrm{~cm}$ away to achieve the same level of success. Essentially, the presence of the toxicant acted to increase the sperm dilution effects (by either reducing the concentration of live sperm or the number of successful sperm interactions). The fact that copper reduces the distance over which successful fertilisation can occur, combined with other typical effects of pollutants, has serious implications for the effect of this pollutant on zygote production and recruitment more generally. Pollutants can greatly reduce the density of individuals, thus increasing the distance between spawning males and females (Johnston \& Keough 2002). Finally, pollutants can also significantly affect the size of eggs produced by mothers (Cox \& Ward 2002). Given that smaller eggs are smaller 'targets' for sperm and, therefore, are less likely to be fertilised (Levitan 1996), this will further reduce fertilisation rates. Thus, pollutants can negatively impact fertilisation success in 3 ways that are likely to act in synergy: (1) increasing the distance between spawners through density reductions, (2) making eggs less fertilisable and (3) effectively increasing sperm dilution rates. We are aware of no studies that examine sperm production after exposure to pollutants, but if this too is affected then fertilisation rates in polluted environments could effectively be zero. Regardless, our results show that the distance among spawning individuals needs to be decreased (or the amount of sperm released increased) in order to ensure high rates of fertilisation success in the presence of a toxicant. The sensitivity of gametes, combined with the other potential effects of toxicants, suggests that marine pollution could be having greater impacts on the reproductive success of broadcast spawning invertebrates than previously anticipated.

Acknowledgements. We gratefully acknowledge help in the field provided by Jane McKenzie, Bronwyn Cumbo, Katherine Dafforn, Emma Hollows, Anna Louise Hollows, Gabi Hollows, Stephanie Compton and Edward Mackay. We thank Mick Keough and Yvonne Buckley for helpful discussions regarding the strength and weakness of various analytical approaches. This manuscript benefited greatly from comments by 4 anonymous reviewers and Roger Hughes. This study was supported by grants from the Australian Research Council to E.L.J. and D.J.M.

\section{LITERATURE CITED}

Allee WC (1931) Animal aggregations: a study in general sociology. University of Chicago Press, Chicago, IL

ANZECC (Australian and New Zealand Environment and Conservation Council) (2000) Australian and New Zealand guidelines for fresh and marine water quality, Vol 1. The guidelines. ANZECC Report No. 4
Babcock RC, Mundy CN (1992) Reproductive biology, spawning and field fertilisation rates of Acanthaster planci. Aust J Mar Freshw Res 43:525-534

Batley GE, Apte SC, Stauber JL (1999) Acceptability of aquatic toxicity data for the derivation of water quality guidelines for metals. Mar Freshw Res 50:729-738

Brawley SH (1992) Fertilization in natural populations of the dioecious brown alga Fucus ceranoides and the importance of the polyspermy block. Mar Biol 113:145-157

Brawley SH, Johnson LE, Pearson GA, Speransky V, Li R, Serrao EA (1999) Gamete release at low tide in fucoid algae: Maladaptive or advantageous? Am Zool 39:218-231

Coma R, Lasker HR (1997) Small-scale heterogeneity of fertilization success in a broadcast spawning octocoral. J Exp Mar Biol Ecol 214:107-120

Cox EF, Ward S (2002) Impact of elevated ammonium on reproduction in two Hawaiian scleractinian corals with different life history patterns. Mar Pollut Bull 44:1230-1235

Denny MW, Shibata MF (1989) Consequences of surf-zone turbulence for settlement and external fertilization. Am Nat 134:859-889

Denny MW, Dairiki J, Distefano S (1992) Biological consequences of topography on wave-swept rocky shores. I. Enhancement of external fertilization. Biol Bull (Woods Hole) 183:220-232

Dinnel PA, Link JM, Stober QJ (1987) Improved methodology for a sea-urchin sperm cell bioassay for marine waters. Arch Environ Contam Toxicol 16:23-32

Dinnel PA, Link JM, Stober QJ, Letourneau MW, Roberts WE (1989) Comparative sensitivity of sea-urchin sperm bioassays to metals and pesticides. Arch Environ Contam Toxicol 18:748-755

Franchet C, Goudeau M, Goudeau H (1997) Mercuric ions impair the fertilisation potential, the resumption of meiosis, the formation of the male pronucleus, and increase polyspermy, in the egg of the ascidian Phallusia mammillata. J Exp Zool 278:255-272

Franchet C, Goudeau M, Goudeau H (1999) Tributyltin impedes early sperm-egg interaction at the egg coat level in the ascidian Phallusia mammillata but does not prevent sperm-egg fusion in naked eggs. Aquat Toxicol 44: 213-228

Franke ES, Babcock RC, Styan CA (2002) Sexual conflict and polyspermy under sperm-limited conditions: in situ evidence from field simulations with the free-spawning marine echinoid Evechinus chloroticus. Am Nat 160:485-496

Hall LW, Scott MC, Killen WD (1998) Ecological risk assessment of copper and cadmium in surface waters of Chesapeake Bay watershed. Environ Toxicol Chem 17:11721189

Haynes D, Loong D (2002) Antifoulant (butyltin and copper) concentrations in sediments from the Great Barrier Reef World Heritage Area, Australia. Environ Pollut 120:391396

Johnston EL, Keough MJ (2002) Direct and indirect effects of repeated pollution events on marine hard-substrate assemblages. Ecol Appl 12:1212-1228

Levitan DR (1991) Influence of body size and population density on fertilization success and reproductive output in a free-spawning invertebrate. Biol Bull (Woods Hole) 191: 261-268

Levitan DR (1995) The ecology of fertilization in free-spawning invertebrates. In: McEdward LR (ed) Ecology of marine larvae. CRC Press, Boca Raton, FL, p 124-152

Levitan DR (1996) Effects of gamete traits on fertilisation in the sea and the evolution of sexual dimorphism. Nature 382:153-155 
Levitan DR (2002) Density-dependent selection on gamete traits in three congeneric sea urchins. Ecology 83:464-479

Levitan DR (2004) Density dependent sexual selection in external fertilizers: variances in male and female fertilization success along the continuum from sperm limitation to sexual conflict in the sea urchin Strongylocentrotus franciscanus. Am Nat 164:298-309

Levitan DR, Petersen C (1995) Sperm limitation in the sea. Trends Ecol Evol 10:228-231

Levitan DR, Sewell MA, Chia FS (1991) Kinetics of fertilization in the sea urchin Strongylocentrotus franciscanus: interaction of gamete dilution, age, and contact time. Biol Bull (Woods Hole) 181:371-378

Marshall DJ (2002) In situ measures of spawning synchrony and fertilization success in an intertidal, free-spawning invertebrate. Mar Ecol Prog Ser 236:113-119

Marshall DJ (2006) Reliably estimating the effect of toxicants on fertilisation success in marine broadcast spawners. Mar Pollut Bull 52:734-738

Marshall DJ, Evans JP (2005) The benefits of polyandry in the free-spawning polychaete Galeolaria caespitosa. J Evol Biol 18:735-741

Marshall DJ, Styan CA, Keough MJ (2000) Intraspecific covariation between egg and body size affects fertilisation kinetics of free-spawning marine invertebrates. Mar Ecol Prog Ser 195:305-309

Marshall DJ, Semmens D, Cook C (2004) Consequences of spawning at low tide: limited gamete dispersal for a rockpool anemone. Mar Ecol Prog Ser 266:135-142

Mead KS, Denny MW (1995) The effects of hydrodynamic shear stress on fertilization and early development of the purple sea urchin Strongylocentrotus purpuratus. Biol Bull (Woods Hole) 188:46-56

Meidel SK, Yund PO (2001) Egg longevity and time-integrated fertilization in a temperate sea urchin (Strongylocentrotus droebachiensis). Biol Bull (Woods Hole) 201: $84-94$

Millar RB, Anderson MJ (2003) The kinetics of monospermic and polyspermic fertilization in free-spawning marine invertebrates. J Theor Biol 224:79-85

Editorial responsibility: Roger Hughes (Contributing Editor), Bangor, UK
Negri AP, Heyward AJ (2001) Inhibition of coral fertilization and larval metamorphosis by tributyltin and copper. Mar Environ Res 51:17-27

Pennington JT (1985) The ecology of fertilization of echinoid eggs: the consequences of sperm dilution, adult aggregation and synchronous spawning. Biol Bull (Woods Hole) 169:417-430

Quinn GP, Keough MJ (2002) Experimental design and data analysis for biologists. Cambridge University Press, Cambridge

Quinn JF, Wing SR, Botford LW (1993) Harvest rufugia in marine invertebrate fisheries: models and applications to the red sea urchin, Strongylocentrotus franciscanus. Am Zool 33:537-550

Reichelt-Brushett AJ, Harrison PL (2005) The effect of selected trace metals on the fertilization success of several scleractinian coral species. Coral Reefs 24:524-534

Reichelt-Brushett AJ, Michalek-Wagner K (2005) Effects of copper on the fertilization success of the soft coral Lobophytum compactum. Aquat Toxicol 74:280-284

Ringwood AH (1992) Comparative sensitivity of gametes and early developmental stages of a sea-urchin species (Echinometra mathaei) and a bivalve species (Isognomon californicum) during metal exposures. Arch Environ Contam Toxicol 22:288-295

Styan CA (1998) Polyspermy, egg size and the fertilization kinetics of free-spawning marine invertebrates. Am Nat 152:290-297

Vogel H, Czihak G, Chang P, Wolf W (1982) Fertilization kinetics of sea-urchin eggs. Math Biosci 58:189-216

Williams ME, Bentley MG, Hardege JD (1997) Assessment of field fertilisation success in the infaunal polychaete Arenicola marina (L.). Invertebr Reprod Dev 31:1-3

Yund PO (2000) How severe is sperm limitation in natural populations of marine free-spawners? Trends Ecol Evol 15: 10-13

Zuniga M, Roa R, Larrain A (1995) Sperm cell bioassays with the sea-urchin Arbacia spatuligera on samples from two polluted Chilean coastal sites. Mar Pollut Bull 30: 313-319

Submitted: April 19, 2006; Accepted: August 16, 2006 Proofs received from author(s): February 19, 2007 